\title{
Role of SHG in Poverty Reduction
}

\author{
Nidhi $^{1 *}$, B.N. Kalsariya ${ }^{1}$, Sujata Parmar $^{1}$ and Devendra Kumar Meena ${ }^{2}$ \\ ${ }^{1} J A U$, Junagadh, India \\ ${ }^{2}$ SKNAU, Jobner, India \\ *Corresponding author
}

A B S T R A C T

\begin{tabular}{|l|}
\hline Ke y w or d s \\
Income, SHG, \\
Poverty
\end{tabular}

\section{Introduction}

Poverty actually means of those who have nothing, people whose lives are in constant danger due to the lack of all basic resources that are required for their survival. In general, extreme poverty means extreme deprivation i.e. deprivation of all basic amenities of life. It is seen that along with the urbanization and modernization people met with different forms of poverty and every definitions related to poverty are also changes with the inclusion of new dimensions.

Removal of poverty is the main objective of planning in India since from the inception of planning periods. The poverty alleviation programmes have been given greatest importance in the field of economic development. For the removal of poverty, a direct anti-poverty scheme is required so that it can combat with all those factors which tend to increase the forces of poverty in the both rural and urban areas.

But the process of poverty alleviation can be more sustainable when all the members of the family are involved. Therefore, reduction of poverty should be an important concern of the developing countries in order to attain economic development and welfare of the people. For alleviating rural poverty and freeing the rural masses from the vicious circle of poverty, a direct implementation of anti-poverty scheme is urgently required for which credit has long been identified as one of the most crucial input for the upliftment of people. 
The self-help group (SHG) approach is a new paradigm into the field of rural development which main objectives are to increase the well-being of the poor people, provide access to resources and credit, increase selfconfidence, self-esteem and increase their creditability in all aspects of lives. The poverty alleviation intervention of the SHG is in the form of undertaking economic programmes to provide employment, giving micro finance services to the poor so that they can get themselves acquainted with skills and occupational diversification.

\section{Materials and Methods}

In order to realize the objective of the study, 180 SHG women members were selected from 18 villages of the 6 talukas of Junagadh and Rajkot districts of Saurashtra region by employing multistage, purposive and random sampling technique. The ex post facto research design was adopted, since the phenomenon has already occurred and is continuing. An interview schedule was developed in accordance with the objectives of the study and it was pre tested and translated into Gujarati. The data of this study were collected with the help of structural interview schedule. The collected data were classified, tabulated, analyzed and interpreted in order to make the findings meaningful.

\section{Results and Discussion}

Poverty actually means of those who have nothing, people whose lives are in constant danger due to the lack of all basic resources that are required for their survival. In general, extreme poverty means extreme deprivation i.e. deprivation of all basic amenities of life. It is seen that along with the urbanization and modernization people met with different forms of poverty and every definitions related to poverty are also changes with the inclusion of new dimensions.
In the present study, we tried to analyze the role of Self Help Groups in the poverty reduction of SHG women members with the help of comparison in between their monthly income before joining the Self Help Group and after joining of the Self Help Group.

Income is directly or indirectly playing the important role in poverty reduction because it helps in the improvement of their living standard.

A perusal of the data in table 1 and 2 revealed that before joining of the SHG monthly income of the (48.88 per cent) respondents was in the range of ₹ 1000 to 2000 per month whether after joining of the SHG no one respondent had ₹ 1000 to 2000 per month income. Whereas, 42.22 per cent of the respondents were getting the ₹ 2001 to 3000 per month income before joining the SHG but after joining the only 14.44 per cent were getting the income in the range of ₹ 2001 to 3000 per month income.

On the other hand, only 8.89 per cent of the respondents were getting the per month income of ₹ 3001 to 4000 but after maximum 50.56 per cent of the respondents were getting the monthly income of ₹ 3001 to 4000 . Before joining of the SHG no one respondent was getting ₹ 4001 to 5000 monthly income and after joining of the SHG 31.11 per cent of the respondents were getting the monthly income in the range of ₹ 4001 to 5000 .

It can also be revealed that no one respondent was getting the monthly income in the range of ₹ 5001 to 6000 and more than ₹ 6000 before joining of the SHG but after joining of the SHG very few only 3.89 per cent of the respondents were getting the monthly income in the range of ₹ 5001 to 6000 and no any change was found in the more than ₹ 6000 monthly income before and after joining of the Self Help Group (Fig. 1 and 2). 
Table.1 Distribution of the respondents according to their monthly income

Before joining of the SHG

\begin{tabular}{|c|l|c|c|}
\hline Sr. No. & $\begin{array}{l}\text { Monthly income before } \\
\text { joining SHG (Rs.) }\end{array}$ & Frequency & Per cent \\
\hline $\mathbf{1}$ & ₹ $1000-2000$ & 88 & 48.89 \\
\hline 2 & $₹ 2001-3000$ & 76 & 42.22 \\
\hline 3 & $₹ 3001-4000$ & 16 & 8.89 \\
\hline 4 & ₹ $4001-5000$ & 00 & 0.00 \\
\hline 5 & ₹ $5001-6000$ & 00 & 0.00 \\
\hline 6 & More than ₹ 6000 & 00 & 0.00 \\
\hline
\end{tabular}

Table.2 Distribution of the respondents according to their monthly income After joining of the SHG

\begin{tabular}{|c|l|c|c|}
\hline Sr. No. & $\begin{array}{l}\text { Monthly income } \\
\text { joining SHG (Rs.) }\end{array}$ & Frequency & Per cent \\
\hline 1 & ₹ $1000-2000$ & 00 & 00.00 \\
\hline 2 & ₹ $2001-3000$ & 26 & 14.44 \\
\hline 3 & ₹ $3001-4000$ & 91 & 50.56 \\
\hline 4 & ₹ $4001-5000$ & 56 & 31.11 \\
\hline 5 & ₹ $5001-6000$ & 07 & 03.89 \\
\hline 6 & More than ₹ 6000 & 00 & 00.00 \\
\hline
\end{tabular}

Fig.1 Distribution of the respondents according to their monthly income Before joining of the SHG

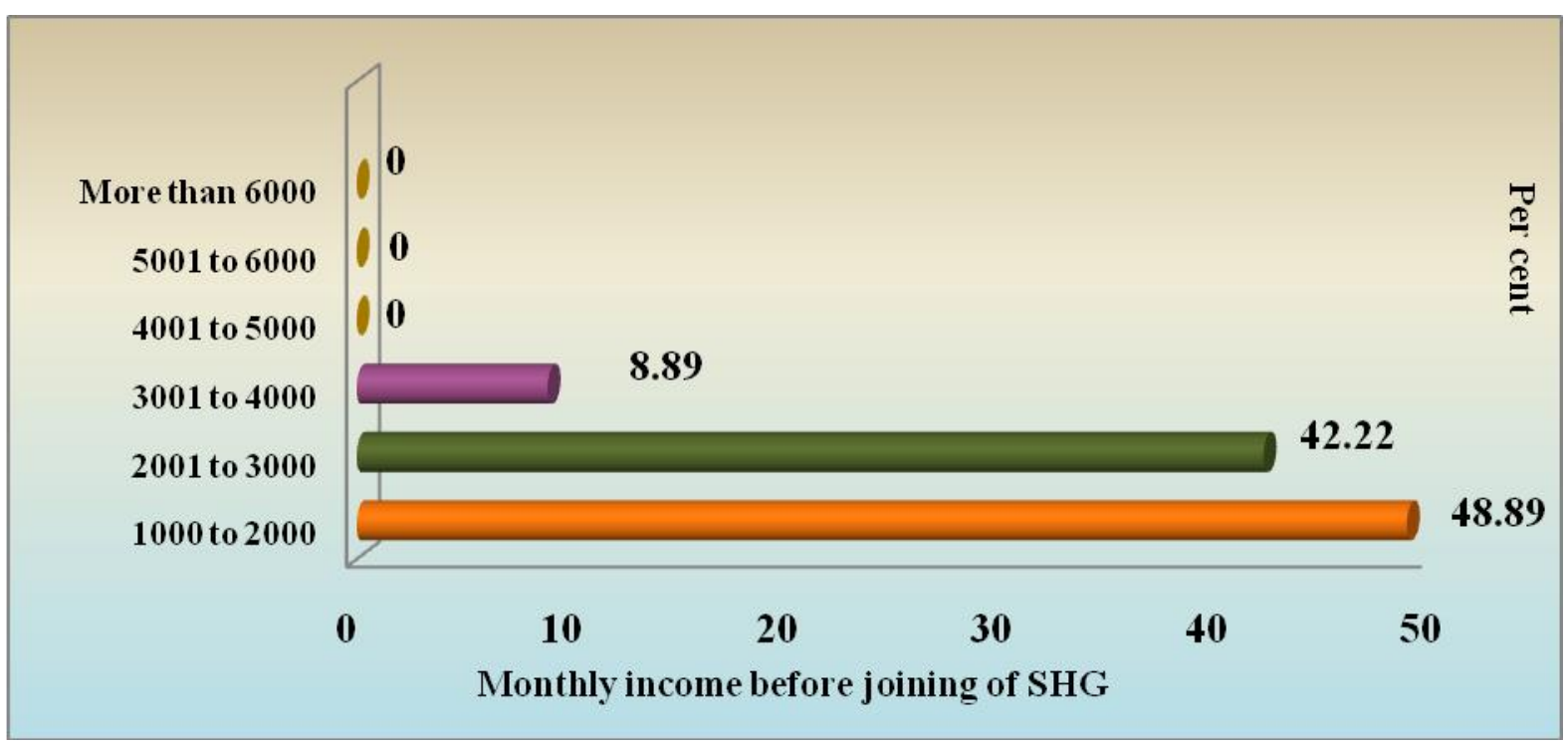


Fig.2 Distribution of the respondents according to their monthly income after joining of the SHG

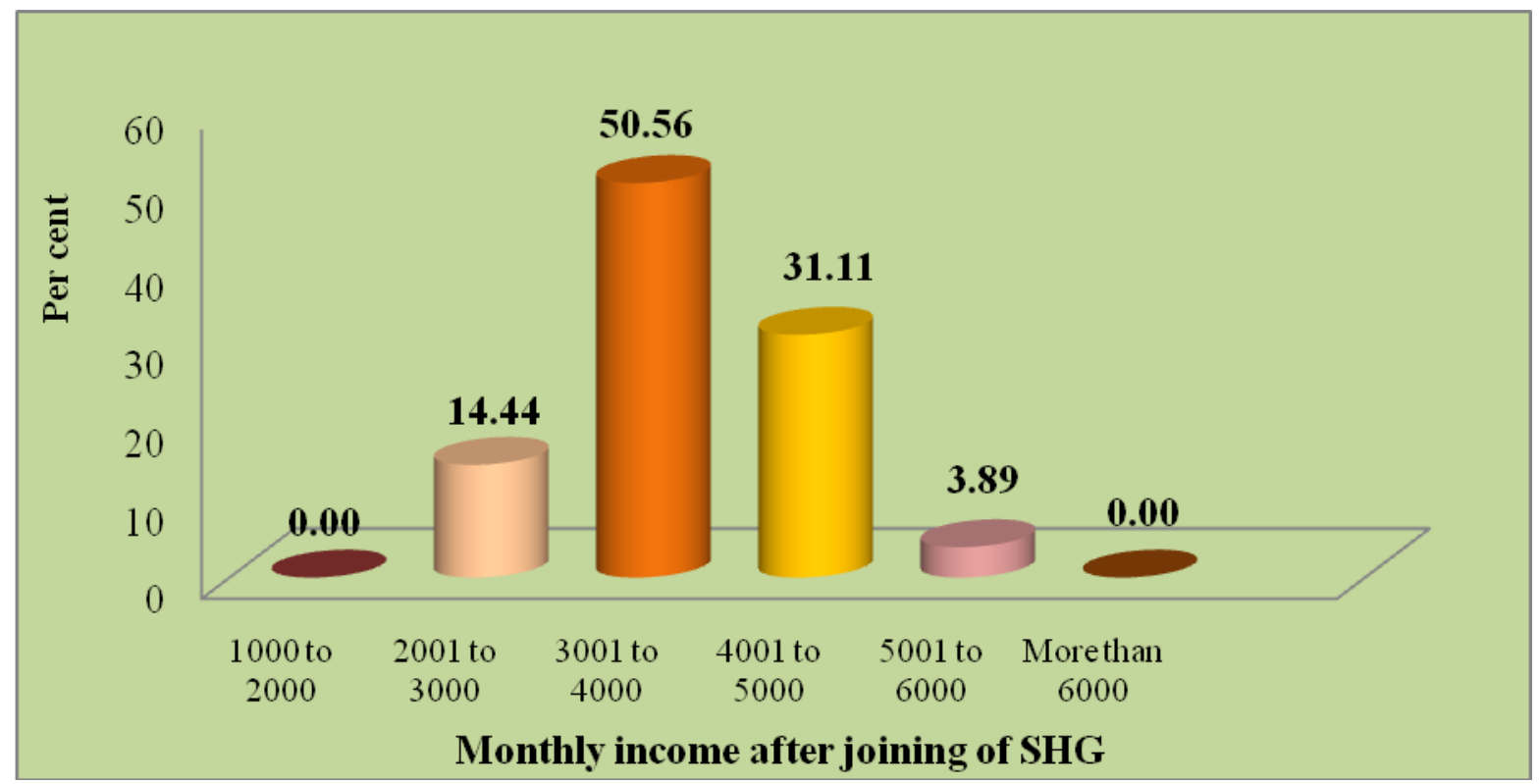

From the above discussion, it can be concluded that there was resultant change in the monthly income of the respondents before and after joining of the Self Help Group.

The probable reason might be that in Self Help Groups women are engaged in various income generating activities which increases their income and that also the main goal of the SHG members behind joining of the SHG. This finding is in line with the finding of Kalirajan and Singh (2012) and Maurya (2014).

\section{References}

Kalirajan, K. and Singh, K. 2012. Self Help Group-Banking poverty reduction nexus: A case study of Uttarakhand State, India. ASARC Working Paper, pp: 2-24.

Maurya, H. 2014. Impact of microfinance on poverty eradication through SHGs: A Case study of Pratapgarh District (Uttar Pradesh). International Journal of Science and Research. 12(3): 27102714.

\section{How to cite this article:}

Nidhi, B.N. Kalsariya, Sujata Parmar and Devendra Kumar Meena. 2018. Role of SHG in Poverty Reduction. Int.J.Curr.Microbiol.App.Sci. 7(08): 1489-1492.

doi: https://doi.org/10.20546/ijcmas.2018.708.169 